REPORT

\title{
Preliminary identification of core domains for outcome studies in psoriatic arthritis using Delphi methods
}

\section{W J Taylor}

Ann Rheum Dis 2005;64(Suppl II):ii1 10-ii1 12. doi: 10.1136/ard.2004.030874

\begin{abstract}
Objective: To develop a consensus based set of core domains for outcome studies in psoriatic arthritis.

Methods: A list of 26 potential domains was prepared through literature review and email discussions amongst the GRAPPA steering committee members and scored by rheumatologists identified through membership of the CASPAR study and the steering committee. Each participant was emailed an up to date review of outcome measures in psoriatic arthritis and asked to distribute 100 points amongst each potential domain. In two subsequent rounds the group median, interquartile range, and earlier responses were emailed to each respondent to provide an opportunity to revise their scoring.

Results: Thirty two participants responded to the first round, of whom 30 responded to the third round. For DC-ART, the highest scoring domains were actively inflamed joint count, radiological damage score, patient global assessment, pain, physical function, acute phase response, and quality of life (scores 7 to 12). For SMARD, the highest scoring domains were pain, patient global assessment, physical function, quality of life, and active joint count (scores 10 to 18). For clinical record keeping, three domains scored highly at 10 (pain, patient global assessment, and active joint count). For rehabilitation, the highest scoring domains were physical function, quality of life, pain, patient global assessment, work limitations, and work incapacity (scores 10 to 15).

Conclusion: Amongst rheumatologists with an interest in psoriatic arthritis, a reduced list of potential standard outcome domains have been defined by Delphi consensus methods.
\end{abstract}

$\mathrm{P}$ soriatic arthritis is manifest in diverse ways including: peripheral joint pain and swelling, spinal pain and stiffness, articular damage, enthesitis, dactylitis, iritis, and skin psoriasis. ${ }^{1}$ Such disease manifestations may affect a number of areas of life-for example, joint range of motion, radiographic appearances, functional status, quality of life, utility, or work capacity. It is unclear which, of a large number of potential domains, are most relevant for including in a core set of endpoints in studies of psoriatic arthritis. Core sets for appropriate standard endpoints are useful for limiting statistical errors by reducing the number of variables to be analysed and also to enable valid pooling of results across different studies. Such core sets are now available in rheumatoid arthritis, osteoarthritis, and ankylosing spondylitis. ${ }^{2-4}$

The objective of this study was to determine which domains rheumatologists felt were most relevant to the assessment of outcome studies of psoriatic arthritis using structured Delphi methodology. The process developed by the

ASsessment in Ankylosing Spondylitis (ASAS) group was largely followed. ${ }^{4}$

\begin{abstract}
METHODS
A search of the literature, formalised into a review paper concerning outcome assessments in psoriatic arthritis, ${ }^{5}$ was used to develop a list of 26 potential outcome domains. These were discussed and refined using electronic communication by the steering committee of the Group for Research and Assessment of Psoriasis and Psoriatic Arthritis (GRAPPA). Four contexts of measurement were identified, based on the ASAS process (except that "physical therapy" was broadened to include other rehabilitation interventions and was relabelled "rehabilitation"):

- disease controlling antirheumatic therapy (DC-ART)

- symptom modifying antirheumatic drugs (SMARDs)

- rehabilitation

- clinical record keeping.
\end{abstract}

Potential participants were selected on the basis of a major interest in psoriatic arthritis and included investigators from Australasia, Europe, and North America of the multinational ClASsification of Psoriatic ARthritis (CASPAR) study and other individual rheumatologists nominated by members of the steering committee. A total of 50 rheumatologists were invited to participate.

A Delphi process ${ }^{6}$ was developed whereby each participant was asked to determine the relative importance of each domain by distributing 100 points amongst the 26 domains. Respondents were free to assign points to as many or as few domains as they wished. The number of points assigned to any particular domain reflected its relative importance, with more points being assigned to more important domains. Each of the four measurement contexts was scored separately. In subsequent rounds, participants were given their own response and the group opinion for each domain (median and interquartile range) from the previous round. Respondents were able to submit new scores or leave their scores unchanged. Three rounds were conducted by electronic mail or facsimile.

In addition, with the first round, participants were given the review of assessment methods in PsA.

\section{RESULTS}

A total of 32 rheumatologists responded to the first round (response rate 64\%), and all but two of them responded to the third and final round. The second round results of these two participants were carried forward. The main effect of the feedback process was to reduce variability in scores assigned

Abbreviations: DC-ART, disease controlling antirheumatic therapy; SMARD, symptom modifying antirheumatic drug 

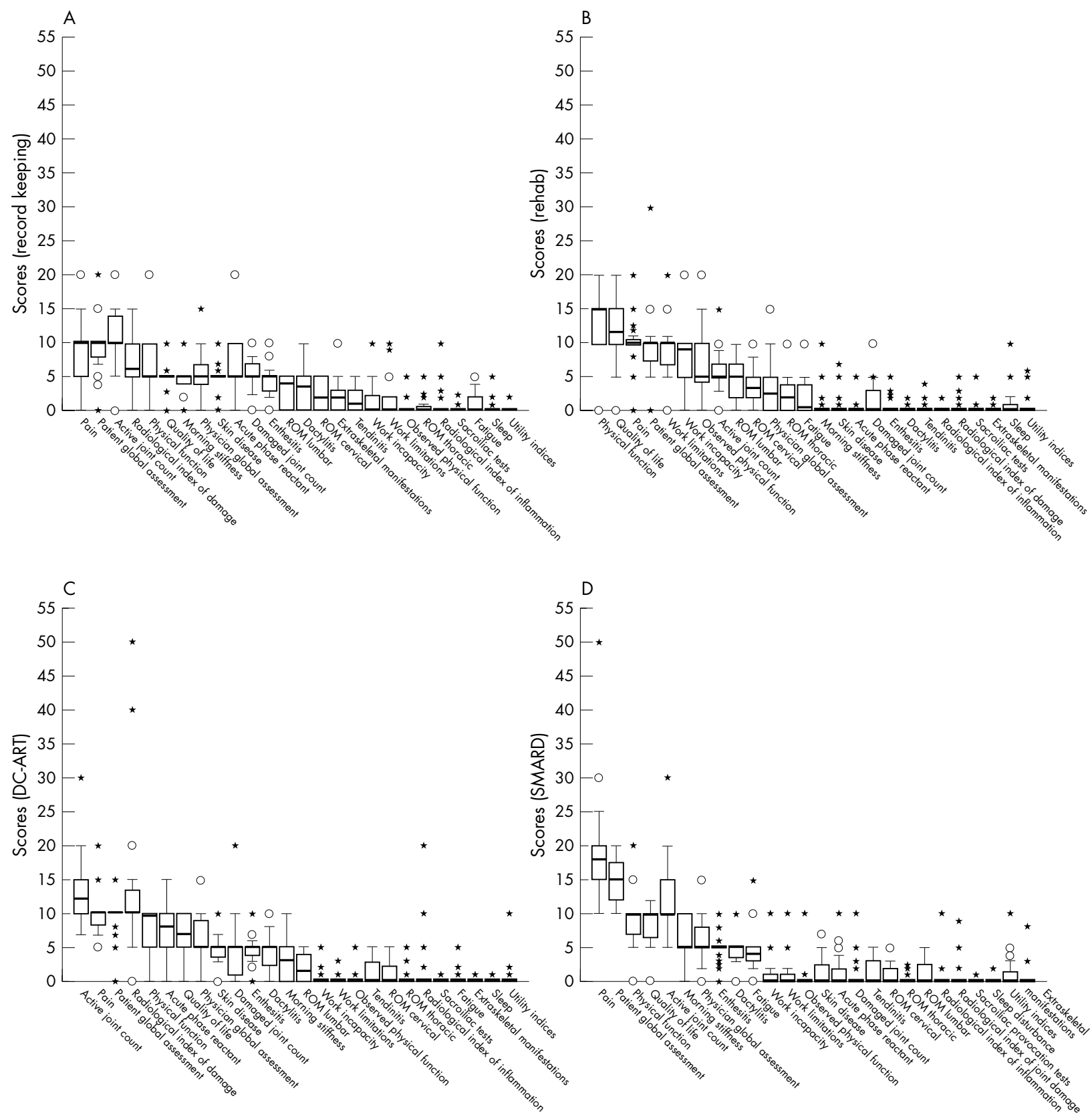

Figure 1 Box plot distribution of scores for each domain (median, interquartile range (IQR), 90\% confidence interval, outliers (1.5-3 IQR beyond median) and extremes (beyond 3 IQR from median)). (A) Clinical record keeping; (B) rehabilitation; (C) disease controlling antirheumatic therapy (DC$A R T) ;(D)$ symptom modifying antirheumatic drugs (SMARD). ROM, range of motion.

to each domain, but there was little change in the relative ranking of each domain over the course of the three rounds (data not shown).

The distribution of the scores assigned to the 26 domains at the third round is shown in fig 1 . There was reasonably clear consensus about the importance of several domains in each measurement context (table 1), although a core set of a limited number of domains was not identified.

\section{DISCUSSION}

Using structured consensus methods, this exercise reduced the number of potential domains for consideration in a core set from 26 to around a dozen. While there is an indication of a small number of very important domains in each measurement context, this study does not provide sufficient consensus to decide which of the lower scoring domains should be included in a core set.

There are a number of additional limitations to this exercise. Firstly, a relative under-importance given by rheumatologists to skin disease assessment was observed (median scores of 5 for DC-ART and clinical record keeping, 0 for SMARD and rehabilitation). This is likely due to the contexts of measurements that were "borrowed" from ankylosing spondylitis and rheumatoid arthritis. Respondents were asked to consider "antirheumatic" interventions. A broader view of psoriatic arthritis (for example, from dermatologists or patients) may rate skin disease as of greater relevance.

Secondly, no consideration was given to the possibility that different subgroups of psoriatic arthritis (for example, 
Table 1 Summary of domains selected by the Delphi exercise (median score)

\begin{tabular}{|c|c|c|c|c|}
\hline & Record keeping & Rehabilitation & DC-ART & SMARD \\
\hline $\begin{array}{l}\text { Higher } \\
\text { scoring } \\
\text { domains }\end{array}$ & $\begin{array}{l}\text { Pain, patient global, active } \\
\text { joint count (10) }\end{array}$ & $\begin{array}{l}\text { Pain, patient global, physical } \\
\text { function, QOL, work limitations, } \\
\text { work incapacity (10-15) }\end{array}$ & $\begin{array}{l}\text { Active joint count, radiological damage, } \\
\text { patient global, pain, physical function, } \\
\text { acute phase reactant, QOL (7-12) }\end{array}$ & $\begin{array}{l}\text { Pain, patient global, physical } \\
\text { function, QOL, active joint } \\
\text { count (10-18) }\end{array}$ \\
\hline $\begin{array}{l}\text { Lower } \\
\text { scoring } \\
\text { domains }\end{array}$ & $\begin{array}{l}\text { Radiological damage, physical } \\
\text { function, QOL, morning stiffness, } \\
\text { physician global, skin, acute phase } \\
\text { reactant, damaged joint count, } \\
\text { enthesitis, dactylitis, lumbar ROM } \\
(4-5)\end{array}$ & $\begin{array}{l}\text { Observed physical performance, } \\
\text { active joint count, lumbar ROM } \\
\text { (5-7) }\end{array}$ & $\begin{array}{l}\text { Skin, physician global, enthesitis, } \\
\text { damaged joint count, dactylitis (5) }\end{array}$ & $\begin{array}{l}\text { Morning stiffness, physician } \\
\text { global, enthesitis, dactylitis, } \\
\text { fatigue }(4-5)\end{array}$ \\
\hline
\end{tabular}

predominant axial disease) may require different core sets. This may, for example, explain the large number (14) of domains for DC-ART with a median score of greater than zero. Domains similar to the core sets of both ankylosing spondylitis and rheumatoid arthritis, as well as quality of life and skin disease, had final median scores of greater than zero. A reduction in domains may be more possible for well defined subgroups of psoriatic arthritis.

Finally, the relatively narrow perspective of the respondents (rheumatologists, some with expertise in clinical epidemiology) may limit the validity of the results. It is clearly necessary to gain a wider perspective-from patients themselves as well as the dermatology community. Face to face meetings between a broader representation of rheumatologists, as well as dermatologists, to refine further the prioritisation of measurement domains would be a useful step forward towards identifying a core set for clinical studies in psoriatic arthritis.

\section{ACKNOWLEDGEMENTS}

The participation of the following rheumatologists in this Delphi exercise is gratefully acknowledged: A Adebajo, C Antonio, $\mathrm{K}$ de Vlam, O Fitzgerald, P Helliwell, A Isdale, D Gladman, A Kalla, A Kavanaugh, L Kay, M A Khan, M Lassere, U Lindqvist, E Lubrano, A Marchesoni, H Mielants, D McGonagle, N McHugh, P Mease,
G Mody, P Nash, I Olivieri, K Pile, P Rahman, C Ritchlin, A Russell, C Salvarani, D Symmons, JC Torre-Alonso, D van der Heijde, H Zmierczak.

Correspondence to: Dr W J Taylor, Rehabilitation Teaching and Research Unit, Wellington School of Medicine and Health Sciences, University of Otago, PO Box 7343, Wellington, New Zealand; wtaylor@ wnmeds.ac.nz

\section{REFERENCES}

1 Taylor WJ. The epidemiology of psoriatic arthritis. Curr Opin Rheumatol 2002; 14:98-103.

2 Tugwell P, Boers M. Developing consensus on preliminary core efficacy endpoints for rheumatoid arthritis clinical trials. OMERACT Committee. J Rheumatol 1993;20:555-6.

3 Bellamy N, Kirwan J, Boers $M$, Brooks P, Strand V, Tugwell P, et al. Recommendations for a core set of outcome measures for future phase III clinical trials in knee, hip, and hand osteoarthritis. Consensus development at OMERACT III. J Rheumatol 1997;24:799-802.

4 van der Heijde D, Bellamy N, Calin A, Dougados M, Khan MA, van der Linden S. Preliminary core sets for endpoints in ankylosing spondylitis. Assessments in Ankylosing Spondylitis Working Group. J Rheumatol 1997;24:2225-9.

5 Gladman DD, Helliwell P, Mease P, Nash P, Ritchlin C, Taylor W. Assessment of patients with psoriatic arthritis: a review of currently available measures. Arthritis Rheum 2004:50:24-35.

6 Jones J, Hunter D. Qualitative research: consensus methods for medical and health services research. BMJ 1995; $311: 376-80$ 